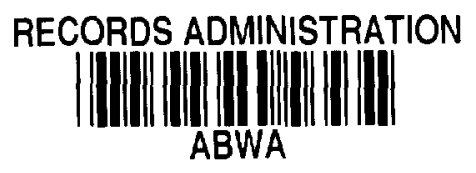

$\underset{\mathrm{DP}-\mathrm{MS}-80-36}{A C C^{\#}}$

RECOVERY OF AMERICIUM-241 FROM AGED PLUTONIUM METAL

by

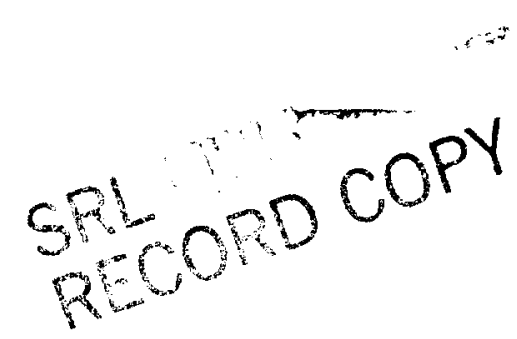

A paper accepted for presentation at the Symposium on "IndustrialScale Production-Recovery-Separation of Transplutonium Elements" to be held at the American Chemical Society National Meeting in San Francisco, California, in August 1980

and

accepted for publication as the proceedings of the symposium in the "ACS SYMPOSIUM SERIES."

This paper was prepared in connection with work under Contract No. DE-AC09-76SR00001 with the U.S. Department of Energy. By acceptance of this paper, the publisher and/or recipient acknowledges the U.S. Government's right to retain a nonexclusive, royalty-free license in and to any copyright covering this paper, along with the right to reproduce and to authorize others to reproduce all or part of the copyrighted paper. 


\section{RECOVERY OF AMERICIUM-241 FROM AGED PLUTONIUM METAL}

by

L. W. Gray, G. A. Burney, T. A. Reil1y,

T. W. Wilson, and J. M. McKibben

E. I. du Pont de Nemours \& Company

Savannah River Laboratory

Aiken, South Carolina 29808

\section{INTRODUCTION}

The Savannah River Plant (SRP) was requested to separate approximately $5 \mathrm{~kg}$ of Am-241 from about $850 \mathrm{~kg}$ of nominally $11.5 \%$ Pu-240 metal. After separation and purification, both actinides were precipitated as oxalates and calcined to their respective oxides. The $\mathrm{PuO}_{2}$ was shipped to the Hanford Nuclear Power Reservation for use as fuel in the Fast Flux Test Facility (FFTF); the $24 \mathrm{AmO}_{2}$ was shipped to the Oak Ridge Isotope Sales Pool for use as a component of neutron sources in many fields, predominantly petroleum well-logging.

A large-scale process was developed specifically for SRP application using established technology of dissolution, separation, purification, precipitation, and calcination. However, adaptation of the process to existing facilities required a substantial development effort to control corrosion, to avoid product contamination, to keep the volume of process and waste solutions manageable, and to denitrate solutions with formic acid. The Multipurpose Processing Facility (MPPF), designed for recovery of transplutonium isotopes, was used for the first time for the precipitation and calcination of americium. Also, for the first time, large-scale formic acid denitration was performed in a canyon vessel at SRP.

* The information contained in this article was developed during the course of work under Contract No. DE-AC09-76-SROOOOl with the U.S. Department of Energy. 
CONCEPTUAL PROCESS

Because it was necessary to use a process that would work in existing equipment, a process was designed (diagramed in Figure I) involving the following operations:

- Dissolution. Plutonium metal was dissolved in $1.67 \mathrm{M}$ sulfamic acid at ambient temperature to $60+10 \mathrm{~g} \mathrm{Pu} / \mathrm{L}$. The $\mathrm{PuO}_{2}$ coating on the surface of the metal plus the $\mathrm{PuH}_{\mathrm{x}}$ (where $\mathrm{x}=2.0$ to 2.7) produced from the reaction of $\mathrm{H}_{2}(\mathrm{~g})$ with plutonium metal formed a sludge which was collected and subsequently dissolved separately using hot $14 \mathrm{M} \mathrm{HNO}_{2}$ containing $0.2 \mathrm{M} \mathrm{KF}$.

- Feed Adjustment for Extraction. Dissolver solution was accumulated and diluted to $<6 \mathrm{~g} \mathrm{Pu} / \mathrm{L}$ with $3 \mathrm{M} \mathrm{HNO} 3$. Sodium nitrite was added to oxidize residual sulfamate and $\mathrm{Pu}$ (III) to $\mathrm{Pu}(\mathrm{IV})$.

- Solvent Extraction. Plutonium and americium were separated in a single pass through a set of mixer-settlers using $30 \%$ tri-n-butyl phosphate (TBP) in a n-paraffin hydrocarbon (NPH).

- Plutonium Finishing. The separated plutonium was processed to $\mathrm{PuO}_{2}$ by conventional cation exchange, oxalate precipitation, and calcination methods.

- Americium Feed Adjustment. The aqueous americium-bearing, sodium nitrate/sulfate nitric acid solution was evaporated and acid-stripped. Oxalic acid was added to mask iron and plutonium ions before feeding to a cation exchange column.

- Cation Exchange. Americium was further concentrated and purified by column chromatography using Dowex ${ }^{\oplus} 50 \mathrm{~W} \times 12$ resin. After washing with $\mathrm{H}_{2} \mathrm{SO}_{4}-\mathrm{H}_{2} \mathrm{C}_{2} \mathrm{O}_{4}$ solution, and then with $0.2 \mathrm{M}$ $\mathrm{HNO}_{3}$, the americium was eluted with $5.5 \mathrm{M} \mathrm{HNO}_{3}$.

- Denitration. The eluted $\mathrm{Am}^{-} \mathrm{HNO}_{3}$ solution was evaporated. The nitric acid was reduced to about $0.25 \mathrm{M}$ by semibatch reaction with formic acid; the final concentration of americium was about $2 \mathrm{~g} \mathrm{Am} / \mathrm{L}$.

- Americium Finishing. The americium concentrate was precipitated in small batches by the addition of $0.9 \mathrm{M}$ oxalic acid, digested at ambient temperature, filtered, washed, air-dried, calcined at $700^{\circ} \mathrm{C}$, and packaged for shipment.

\section{LABORATORY DEMONSTRATIONS}

After each processing unit operation, solutions actually generated were used for laboratory demonstrations of the next 
processing unit operation. Processing parameters were adjusted as necessary to obtain a high yield of a high-purity product.

\section{PILOT DEMONSTRATIONS}

After the laboratory demonstrations, pilot cold-chemical demonstrations of formic acid denitration and of precipitation operations were performed in both canyon and MPPF equipment. These demonstration runs confirmed the operating limits which had been established during the laboratory experiments.

The cation exchange process, however, could not be piloted with cold chemicals. Instead, each separate batch was monitored by multiple sampling and rapid analysis of the raffinate during the loading step. Subsequent column loadings from the same batch of Am-24l solution were then adjusted according to the losses determined after the first column-loading of each batch.

\section{PROCESS YIELDS}

The process operated successfully in the plant. More than $98 \%$ of the americium was recovered from the cation exchange column as an acidic nitrate solution. Substantial quantities of sodium, iron, chromium, nickel, sulfate, and phosphate were removed. Decontamination from all impurities was satisfactory; although some chromium and small amounts of nickel, iron, and lead remained. The plutonium metal feed stock contained about 5 ppm natural lead which was not removed by the process. Recovery of americium in the finishing process (oxalate precipitation and calcination) averaged $98.5 \%$. Most of the residual chromium contaminant was removed from the oxalate in decanted supernate and washes. The finished oxide product purity exceeded specifications; i.e., $>95 \% 24{ }^{2} \mathrm{AmO}_{2}$. By selective blending, impurities in the shipped product, predominantly lead and nickel, were kept below $2 \%$.

\section{EXPERIMENTAL PROCEDURES}

All experiments were conducted using normal laboratory glassware. Chemicals used were technical grade chemicals removed directly from process chemical hold tanks where possible; resins were from the same production lots as would be placed in the process column equipment. Cation exchange feed rates were the same as obtainable in plant equipment. 


\section{LABORATORY RESULTS}

Dissolution of Plutonium Metal

Plutonium metal dissolves readily in sulfamic acid $\left(\mathrm{NH}_{2} \mathrm{SO}_{3} \mathrm{H}\right)$ at ambient temperatures according to the reaction

$$
\mathrm{Pu}^{\mathrm{O}}+3 \mathrm{H}^{+} \mathrm{Pu}^{+3}+3 / 2 \mathrm{H}_{2}(\mathrm{~g})
$$

The dissolution rate at ambient temperature was found to depend upon acid concentration and surface area of the metal. Typically, initial batches of solution from the dissolver average $50+5 \mathrm{~g}$ $\mathrm{Pu} / \mathrm{L}$; the concentration increases to $60+10 \mathrm{~g} \mathrm{Pu} / \mathrm{L}$ when using a cycle of 1 hour dissolving time followed by displacement of twothirds of the solution. A more complete treatment of both ambient temperature and elevated temperature dissolving experiments is given elsewhere $(\underline{1}, \underline{2}, \underline{3})$.

\section{Storage of Dissolved Plutonium Solution}

Simulated storage experiments showed (Figure 2) that radiolysis would be insignificant for valence adjustment of $\mathrm{Pu}$ (III) to $\mathrm{Pu}$ (IV).

It was also necessary to assure that plutonium sulfates would not precipitate during storage. The solubility of plutonium vs. nitric acid concentration at various concentrations of sulfate is shown in Figure 3. Since the plutonium concentration in canyon tanks is kept at $\leq 6 \mathrm{~g} \mathrm{Pu} / \mathrm{L}$, nitric acid concentrations as high as $6 \mathrm{M}$ can be tolerated as all flowsheets dilute the sulfate potential to $\leq 0.4 \mathrm{M}$.

\section{Feed Adjustment and Solvent Extraction}

In the laboratory, the plutonium valence can be effectively adjusted to the extractable $\mathrm{Pu}(\mathrm{IV})$ state using $\mathrm{N}_{2} \mathrm{O}_{4}$, NO, heat, or $\mathrm{NaNO}_{2}$. For plant processing, $\mathrm{NaNO}_{2}$ was chosen as it is the method in routine use for normal Purex processing. Heat was not used because sulfamate hydrolysis is more rapid than its oxidation by nitric acid(4) and the hydrolysis product, $\mathrm{NH}_{4}^{+}$, has a higher affinity for cation resin than does $\mathrm{Na}^{+}$ion. Gases were rejected because at present a system is not available to add the gases to canyon tanks. Chemically, either gas $\left(\mathrm{N}_{2} \mathrm{O}_{4}\right.$ or NO) would have been more desirable for downstream processing of the Am-241.

\section{Americium Concentration}

The method of separation results in the americium being diverted to the $2 \mathrm{AW}$ stream of the solvent extraction cycle. The 
calculated predicted volume of this stream for the full campaign was $2.2 \times 10^{6} \mathrm{~L}$. Physical limitations of equipment required that the solution be evaporated in two steps instead of one. The first step could result in a concentration factor of 25 to 50 . The second step included nitric acid stripping and evaporation to the final volume.

The solubilities of $\mathrm{Na}_{2} \mathrm{SO}_{4}$ and $\left(\mathrm{NH}_{4}\right)_{2} \mathrm{SO}_{4}$ (Figure 4) suggest hydrolysis of the sulfamate ion to $\mathrm{NH}_{4}^{+}$and $\mathrm{SO}_{4}{ }^{2-}$ would be better than oxidation with $\mathrm{NaNO}_{2}$, because the solubility of $\mathrm{NaHSO}_{4}$ is exceeded during the first stage of evaporation. However, downstream processing through cation exchange dictates that oxidation, not hydrolysis, must be the mode of destruction of the sulfamate ion.

Sodium americyl sulfate is also relatively insoluble in nitric acid (Table I). The solubility of this salt is also exceeded during the first stage of evaporation. However, subsequent acid stripping of the solutions reduces the nitric acid concentration and the salts redissolve.

The partial decomposition of dissolved TBP in the evaporation step leads to the precipitation of a white organophosphate solid. Complete decomposition to an acid soluble compound required extended boiling of $\geq 10 \mathrm{M}$ nitric acid solutions as would be achieved if the first evaporation step were a factor of 50 . Use of this evaporation factor in the first stage, however, led to excessive corrosion of the stainless steel process equipment.

The first evaporation step was limited to a factor of 25 to hold down the acid concentration to $\leq 9 \mathrm{M}$. The white solids product plugged the ion exchange columns, but could be removed from the column with a water wash.

\section{Cation Exchange Experiments}

Cation exchange experiments were performed with gel and macroporous resins, and with both simulated and authentic plant solutions. Scouting experiments showed that Dowex $50 \mathrm{~W} \times 8$ was more effective; a masking agent was also necessary to obtain adequate column capacity.

Tests are summarized in Table II. The resin capacity for americium is only a few percent of theoretical due to large concentrations of other polyvalent cations. The resin capacity was increased by adding one to two moles of oxalic acid per mole of iron in the feed. Less than $10 \%$ of the iron is retained by the resin. Addition of oxalic acid to both the feed and wash solution effectively separated $>98 \%$ of the iron as well as $>98 \%$ of the trace $\mathrm{Zr}, \mathrm{Nb}$, and $\mathrm{Pu}$ ions. 
Oxalic acid in the feed does not affect the sorption behavior of $\mathrm{Cr}$ and $\mathrm{Ni}$ ions on the cation resin. However, about $75 \%$ of the $\mathrm{Ni}$ (II) ions was in the sorption and wash effluents because resin affinity for divalent $\mathrm{Ni}$ ion is lower than that for trivalent $\mathrm{Cr}$ and Am ions.

More than $99 \%$ of the sodium was separated when two Na-free acid washes were made after sorption. The first wash was about 15 bed volumes of $0.2 \mathrm{M} \mathrm{H}_{2} \mathrm{SO}_{4}-0.05 \mathrm{M} \mathrm{H}_{2} \mathrm{C}_{2} \mathrm{O}_{4}$; the second wash was about 5 bed volumes of $0.25 \mathrm{M} \mathrm{HNO}_{3}$, which removed the remaining sodium and also flushed sulfate and oxalate from the resin bed.

Elution with $5 \mathrm{M} \mathrm{HNO}_{3}$ at $0.5 \mathrm{~mL} /\left(\mathrm{min}-\mathrm{cm}^{2}\right)$ removed about $87 \%$ of the americium in four bed-volumes and $>99 \%$ in eight bedvolumes.

Formic Acid Denitration of Product Solution

Results of formic acid denitration simulation experiments (Figure 5) showed that at $>90^{\circ} \mathrm{C}$, denitration began when sufficient 23.5M formic acid had been added to bring the solution concentration to about $0.06 \mathrm{M}$ formic acid. The lowest free-acid concentrations for the laboratory solutions were obtained when a formic acid-to-free nitric acid mole ratio of about 1.6 to 1.9 was used. This ratio yielded a final free-acid concentration of 0.7 to $0.8 \mathrm{M}$. In the region where free nitric acid is $\langle 3 M$, formic acid begins to accumulate in the solution. This accumulated formic acid is oxidized by refluxing the solution after all formic acid has been added.

To handle the volume of solution (about $30,000 \mathrm{~L}$ ) necessary in the plant operation, a semi-batch denitration was necessary. Slow evaporation during product accumulation reduced the volume to $<12,000 \mathrm{~L}$, but increased the nitric acid concentration to about 11M. Experiments indicated that for a semi-batch denitration mode, a projected nitric acid concentration of $2 M$ was an excellent stoppoint, because no residual formic acid remains through the reflux and evaporation steps. Additional high nitric acid solution can then be added to the evaporated-denitrated solution without autoinitiation of a formic acid-nitric acid reaction. After all the Am-bearing solution had been transferred to the denitration evaporator and denitrated to $\leq 2 M$, the solution could be evaporated to $2500 \mathrm{~L}$ and denitrated to a residual free-acid concentration of 0.5 to $0.8 \mathrm{M}$. In actual practice, the final $2500 \mathrm{~L}$ of solution was denitrated to $0.25 \mathrm{M} \mathrm{HNO}_{3}$.

The lower acidity obtained in the plant-scale run resulted in the precipitation of a small amount of an iron organophosphate material which could be dissolved at $50^{\circ} \mathrm{C}$ in $0.5 \mathrm{M} \mathrm{HNO}_{3}$. There- 
fore, after moving the solution to the hold tank, the denitration evaporator was flushed with $1 \mathrm{M} \mathrm{HNO}_{3}$. This flush raised the acid concentration of the prepared solution to $0.37 \mathrm{M}$ and the volume to $2700 \mathrm{~L}$.

\section{Precipitation of Am-241 Oxalate}

Americium is separated from iron, chromium, nickel, and other impurities by oxalate precipitation. The Am-24l feed solution for precipitation in the MPPF after formic acid denitration and volume reduction was approximately $2 \mathrm{~g} \mathrm{Am} / \mathrm{L}, 14 \mathrm{~g} \mathrm{Cr} / \mathrm{L}, 1.2 \mathrm{~g} \mathrm{Fe} / \mathrm{L}$, and $0.8 \mathrm{~g} \mathrm{Ni} / \mathrm{L}$ in one molar nitric acid. Further concentration of the feed solution to $>2 \mathrm{~g} \mathrm{Am} / \mathrm{L}$ necessitates evaporation at $\left\langle 85^{\circ} \mathrm{C}\right.$ because of the potential corrosion of the stainless steel evaporator resulting from $\mathrm{Cr}(\mathrm{VI})$ in hot strong nitric acid. A precipitation test with plant solution adjusted to $2 \mathrm{~g} \mathrm{Am} / \mathrm{L}$ yielded americium oxide that met purity guidelines (Table III). Emission spectrograph analyses showed 0.25 wt $\% \mathrm{~Pb}, 0.15$ wt $\% \mathrm{Ni}, 0.14 \mathrm{wt} \% \mathrm{Cr}$, and 0.1 wt $\% \mathrm{Fe}$. All other impurities were $<0.1 \mathrm{wt} \%$, and the total impurities were $0.8 \mathrm{wt} \%$. Another test with the plant solution yielded americium oxide with $1.6 \mathrm{wt} \%$ total impurities, and with nickel and chromium each about 0.5 wt \%.

\section{PRELIMINARY PLANT TESTS}

Full-scale simulations of the formic acid denitration and the precipitation of rare earths (simulating americium) were carried out in plant equipment before processing the actual stream containing the Am-241.

\section{Denitration of Nitric Acid}

Three simulated tests were run using only clean nitric and formic acids. In each case, the reaction began promptly and proceeded smoothly. After the second test, the denitrated material was evaporated and additional nitric acid added to simulate the tandem semi-batch operation to be used with actual process solution. At the end of formic acid feed for Test 3, the material was refluxed for 2 hours and evaporated to $2500 \mathrm{~L}$ to simulate the final canyon product batch. A final formic acid denitration reduced the acidity of the simulated concentrate to $<1 \mathrm{M} \mathrm{HNO}_{3}$.

\section{Oxalate Precipitation of Simulated Solutions}

Two precipitation conditions were investigated with dysprosium or samarium as stand-ins for Am-24l. Both conditions were based on 
physical limitations on the volumes in tanks to be used in the Am-241 solution processing. The denitrated product solution could be concentrated in the canyon evaporator; if so, the volume of solution required to just cover the steam coils in this evaporator, nearly $2500 \mathrm{~L}$, would be the minimum volume. Hence, one condition assumed the solution was evaporated to $2500 \mathrm{~L}$, which would give $2 \mathrm{~g}$ $A m / L$. The second condition was set by the maximum volume of MPPF evaporator; i.e., $1850 \mathrm{~L}$. Hence, the second condition assumed the solution was further evaporated to $1800 \mathrm{~L}$, which would give $2.8 \mathrm{~g}$ $\mathrm{Am} / \mathrm{L}$. Cold testing in MPPF used concentrations of contaminant that would be found at both $1800 \mathrm{~L}$ and $2500 \mathrm{~L}$. The cold testing in MPPF confirmed that conditions assuming $2500 \mathrm{~L}$ would yield an acceptably pure product, whereas $1800 \mathrm{~L}$ might yield a marginally pure product.

Later laboratory demonstrations using authentic solutions, however, showed that acceptably pure product could be precipitated from a 4 or $6 \mathrm{~g} \mathrm{Am} / \mathrm{L}$ solution, the equivalent of evaporating the solution to about $900 \mathrm{~L}$. Emission spectrographic analyses showed the total impurities of the americium product from both the 4 and $6 \mathrm{~g} / \mathrm{L}$ solutions to be about $1.5 \mathrm{wt} \%$.

\section{PLANT PROCESSING}

Prior to beginning actual plant processing, it was necessary to flush all tanks and pipes extensively to avoid contamination of the plutonium and the americium with plutonium of a different isotopic composition or with fission products or other impurities. Processing began only after analyses of the flush solutions confirmed the product contamination would be acceptably low.

\section{Plutonium Dissolving}

Plutonium metal was dissolved in $1.67 \mathrm{M}$ sulfamic acid at an average rate of $1.81 \mathrm{~kg}$ per day per dissolver. Sludge and plutonium oxides generated from metal oxidation were dissolved in $\mathrm{HNO}_{3}-\mathrm{HF}$ solutions. This plutonium concentrate (about $60 \mathrm{~g} \mathrm{Pu} / \mathrm{L}$ ) was diluted to 5 to $6 \mathrm{~g} \mathrm{Pu} / \mathrm{L}$ before transfer to canyon storage to meet canyon nuclear safety requirements.

\section{Solvent Extraction}

Feed for the second plutonium cycle was prepared by first oxidizing the $\mathrm{Pu}$ (III) to $\mathrm{Pu}$ (IV) and the sulfamate ion to nitrogen gas and sulfate ion with sodium nitrite. The plutonium was diluted to about $0.5 \mathrm{~g} / \mathrm{L}$ to meet the nuclear safety requirements of the second plutonium cycle. Nitric acid was adjusted to 3.8 to $4.0 \mathrm{M}$ to meet the salting requirements of the solvent extraction separation process. 
Americium and plutonium were separated by one cycle of solvent extraction using $30 \% \mathrm{TBP}$ in a normal paraffin hydrocarbon diluent. Plutonium was extracted while americium was diverted to the aqueous waste stream (2AW).

Plutonium was stripped from the solvent with hydroxylamine, concentrated further by cation exchange, precipitated as plutonium oxalate, and calcined to the oxide.

\section{Evaporation and Steam Stripping}

The aqueous waste stream ( $2 A W$ ) containing the Am-24l was concentrated and stripped of acid using two batch evaporators in the Low Activity Waste (LAW) system. The first concentration step was performed in the LAW batch evaporator. Acid stripping with water and additional evaporation was performed in the second LAW batch evaporator. The average concentration of the Am-24l entering this two-step evaporation process was $3.4 \times 10^{-3} \mathrm{~g} / \mathrm{L}$; after the first step, the Am-241 concentration was 0.08 to $0.15 \mathrm{~g} / \mathrm{L}$; after the second step, the Am-241 concentration was 0.2 to $0.3 \mathrm{~g} / \mathrm{L}$, and the nitric acid concentration was 2.0 to $2.5 \mathrm{M}$.

\section{Cation Exchange}

Feed adjustment consisted of diluting the solution with water such that the concentration of hydrogen ion plus sodium was less than or equal to one molar, and adding oxalic acid (0.03-0.05M) to serve as a complexing agent to facilitate rejection of $\mathrm{Fe}, \mathrm{Zr}-95$, $\mathrm{Nb}-95$, and $\mathrm{Pu}$ ions.

The adjusted solution was fed to a 15-in.-diameter cation exchange column filled with 42 L of Dowex $50 \mathrm{~W} \times 12$ (50 to 100 mesh) resin. After feeding, the column was washed first with $0.25 \mathrm{M}$ $\mathrm{H}_{2} \mathrm{SO}_{4}$ to further remove $\mathrm{Na}, \mathrm{Zr}-95, \mathrm{Nb}-95, \mathrm{Pu}$, and $\mathrm{Fe}$ ions. Next, the column was washed with $0.25 \mathrm{M} \mathrm{HNO}_{3}$ to remove sulfate. Americium was then eluted with $5 \mathrm{M} \mathrm{HNO}_{3}$ and the resin reconditioned with dilute acid for the next run. A summary of typical column operations is given in Table IV.

Slow evaporation $\left(70\right.$ to $80^{\circ} \mathrm{C}$ ) was begun to allow storage of all the product in one tank. This slow evaporation was successful in controlling the corrosion due to chromium in the product.

The isolation system recovered $>98 \%$ of the Am-241, and concentrated the product by a factor of 125 over its most dilute point as $2 \mathrm{AW}$, while rejecting $>96 \%$ of the $\mathrm{Na}^{+}, \mathrm{SO}_{4}{ }^{2-}, \mathrm{Fe}^{3+}, \mathrm{Pu}$, and fission product ions. However, the process recovered $11.2 \%$ of the nickel and $>99 \%$ of. the chromium. 


\section{Formic Acid Denitration}

After the evaporation, approximately $36 \%$ of the Am-241 solution was moved to a denitration evaporator. After dilution from its approximately $11 \mathrm{M}$ to $8 \mathrm{M}$ nitric acid, the acidity of the solution was reduced by reaction with formic acid to an estimated $3 \mathrm{M}$ nitric acid. After refluxing to assure total destruction of the formic acid, the denitrated solution was concentrated in the evaporator to about $55 \%$ of its original volume. A second transfer of Am-241 solution from storage to the denitrated solution was made.

The denitration, refluxing and evaporation were repeated. Four additional transfers, denitrations, refluxings, and evaporations were necessary to move and concentrate all the solution to about $2500 \mathrm{~L}$. Then the final denitration of the entire batch was carried out. All denitrations proceeded smoothly to completion.

Analysis of the final solution indicated no appreciable corrosion of the evaporator during the denitration procedure. The final acidity was lower than that obtained in the laboratory scale experiments, $0.25 \mathrm{M}$ versus $0.7 \mathrm{M}$, respectively.

The lower acidity obtained in the plant scale run resulted in the precipitation of a small amount of the iron, probably as the phosphate. The precipitate was shown to dissolve, in the laboratory, in $0.5 \mathrm{M}$ nitric acid at $50^{\circ} \mathrm{C}$. Therefore, after moving the solution from the evaporator, the evaporator was flushed with $1 \mathrm{M}$ nitric acid. This flush raised the acid concentration of the prepared solution to about $0.37 \mathrm{M}$. These flushes raised the volume to $2700 \mathrm{~L}$.

\section{Precipitation as Oxalate}

Approximately 1500 L of solution was then transferred into the smaller MPPF evaporator. About $150 \mathrm{~L}$ of feed were further transferred into the MPPF as feed for the first four precipitator batches. The remaining $1350 \mathrm{~L}$ were simmered to reduce the volume to $500 \mathrm{~L}$. Additional transfers were made to combine all the feed as well as flush the canyon tanks of all Am-241 products; simmering at $85^{\circ} \mathrm{C}$ continued so that all of the americium-containing solution would fit into the evaporator.

Precipitations were made by adding sufficient $0.9 \mathrm{M}$ oxalic acid to bring the final oxalate concentration to $0.3 \mathrm{M}$. After a digestion period and decanting the filtrate, the oxalate precipitate was washed four times with $0.2 \mathrm{M} \mathrm{H}_{2} \mathrm{C}_{2} \mathrm{O}_{4}-0.7 \mathrm{M} \mathrm{HNO}_{3}$, and once with $0.2 \mathrm{M}\left(\mathrm{NH}_{4}\right)_{2} \mathrm{C}_{2} \mathrm{O}_{4}$. On the initial runs, the washed oxalate precipitate was calcined to a carbonate intermediate to allow 
easier acid dissolution if impurity analysis indicated recycle was required. As all product batches exceeded the purity guidelines, the low-temperature calcination step was eliminated and all products were calcined at $700^{\circ} \mathrm{C}$.

Results for the first 11 runs, all at about $2 \mathrm{~g}^{241} \mathrm{Am} / \mathrm{L}$, are summarized in Table V. $241 \mathrm{AmO}_{2}$ purity was very good (approximately $98 \%$ versus $95 \%$ minimum to meet guideline), and all impurities were insignificant except lead, which averaged $0.44 \%$ (guideline $<0.5 \%$ ), and weight loss, which averaged $0.59 \%$.

Laboratory tests showed that the high weight loss was due to the sorption of water from the air during handling of the calcined powder.

\section{LITERATURE CITED}

1. Gray, L. W., "The Kinetics of the Ambient Temperature Dissolution of Plutonium Metal in Sulfamic Acid," USDOE Report DP-1484, E. I. du Pont de Nemours \& Co., Savannah River Laboratory, Aiken, S.C., 1978.

2. Gray, L. W., "Dissolution of Plutonium Metal in Sulfamic Acid at Elevated Temperatures," USDOE Report DP-1515, E. I. du Pont de Nemours \& Co., Savannah River Laboratory, Aiken, S.C., 1979 .

3. Gray, L. W., "Rapid Dissolution of Plutonium Metal in Sulfamic Acid Followed by Conversion to a Nitric Acid Medium," accepted for publication in Nucl. Technol., MS. 3826.

4. Gray, L. W., "The Interactions of Hydrazine, Ferrous Sulfamate, Sodium Nitrite, and Nitric Acid in Nuclear Fuel Processing Solutions," Nucl. Technol., 1978, 40 (185-193). 
LIST OF FIGURES

FIGURE 1. Process for Recovery of Americium-241 from Aged Plutoni um Meta1

FIGURE 2. Radiolytic Oxidation of Pu(III) to Pu(IV) in Sulfamic Acid - Nitric Acid Solutions

FIGURE 3. Calculated Equilibrium Concentrations of $\mathrm{Pu}(\mathrm{IV})$ in Nitric Acid Solutions Containing Sulfate Ions

FIGURE 4. Solubility of Sulfate Salts in Nitric Acid Solutions

FIGURE 5. Formic Acid Denitration of $241_{\text {Am Solutions }}$ Containing Gross Quantities of Chromium Nitrate 
TABLE I. Solubility of Sodium Americy1 Sulfate

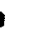

Composition of Solutions a

$\mathrm{HNO}_{3}, \mathrm{M} \quad \mathrm{Na}^{+}, \mathrm{M} \quad \mathrm{SO}_{4}^{2-}, \mathrm{M}$

0.8

2.1

1.0

1.1

1.5

3.3

2.1

3.1

4.2

1.0

1.5
Am in solution, $g / L$ (in equilibrium with solid)
0.15
0.25
0.15
0.4
0.2

a. All solutions contained $\mathrm{Fe}(1.5 \mathrm{~g} / \mathrm{L})$, $\mathrm{Cr}(0.4 \mathrm{~g} / \mathrm{L})$, and $\mathrm{Ni}(0.2 \mathrm{~g} / \mathrm{L})$. 
TABLE II. Capacity of Dowex 50W x 8 for Americium Retention

\begin{tabular}{|c|c|c|c|c|c|}
\hline \multirow[b]{2}{*}{ Test } & \multicolumn{2}{|c|}{ Feed Compositiona } & \multicolumn{2}{|l|}{ 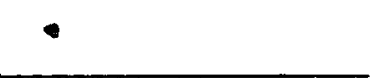 } & \multirow{2}{*}{$\begin{array}{l}\text { Capacity of } \\
\text { Resin, Bed } \\
\text { Volumes }\end{array}$} \\
\hline & $\mathrm{Fe}, \mathrm{g} / \mathrm{L}$ & $\mathrm{Cr}, \mathrm{g} / \mathrm{L}$ & $\mathrm{Ni}, \mathrm{g} / \mathrm{L}$ & $\begin{array}{l}\text { Oxalic } \\
\text { Acid, M }\end{array}$ & \\
\hline 1 & 0.1 & 0.05 & 0.02 & - & 52 \\
\hline 2 & 0.3 & 0.15 & 0.05 & - & 35 \\
\hline 3 & 0.1 & 0.05 & 0.02 & 0.005 & 70 \\
\hline 4 & 1.5 & 0.4 & 0.2 & 0.05 & 40 \\
\hline 5 & 3.5 & 1.3 & 0.7 & 0.1 & 12 \\
\hline 6 & 1.7 & 0.6 & 0.35 & 0.05 & 55 \\
\hline
\end{tabular}

a. Feeds for Tests 1 through 5 were $0.5 \mathrm{M} \mathrm{H}^{+}, 0.4 \mathrm{M} \mathrm{Na}^{+}$, $0.25 \mathrm{M} \mathrm{SO}_{4}{ }^{2-}$, and $0.07 \mathrm{~g} \mathrm{Am} / \mathrm{L}$. Feed for Test 6 was $0.25 \mathrm{M} \mathrm{H}^{+}, 0.2 \mathrm{M} \mathrm{Na}^{+}, 0.125 \mathrm{M} \mathrm{SO}_{4}{ }^{2-}$, and $0.035 \mathrm{Am} / \mathrm{L}$.

- Trademark of Dow Chemical Co., Midland, Michigan. 
TABLE III. $24 \mathrm{AmO}_{2}$ Purity Guidelines

Final Product

Component

Compsition, \%

$\mathrm{AmO}_{2}{ }^{\mathrm{a}}$

$\geq 95$

$\mathrm{Pu}$

$\leq 0.5$

$\mathrm{Pb}$

$\leq 0.5$

Any other element ${ }^{b}$

$<0.5$

a. Calorimetry as the assay method.

b. Determined by emission spectrographic analyses. 
TABLE IV. Typical Column Runs

\begin{tabular}{lccc} 
Component & Feed & Product & Recovery, $\%$ \\
\cline { 2 - 2 } & $40-60$ & $39.2-58.8$ & $>98$ \\
$\mathrm{Au}, \mathrm{g}$ & $0.3-0.6$ & $<0.01$ & $<2$ \\
$\mathrm{Na}, \mathrm{g}$ & $7,000-14,000$ & $\sim 25$ & $\sim 0.3$ \\
$\mathrm{SO}_{4}, \mathrm{~g}$ & $14,000-28,000$ & $\sim 300$ & $\sim 1$ \\
$\mathrm{Fe}, \mathrm{g}$ & $1,000-3,000$ & $\sim 30$ & $\sim 1$ \\
$\mathrm{Cr}, \mathrm{g}$ & $300-900$ & $300-900$ & $>99$ \\
$\mathrm{Ni}, \mathrm{g}$ & $150-450$ & $15-100$ & $\sim 20$ \\
$\mathrm{Vol}, \mathrm{L}$ & 1,500 & 325 & - \\
$\mathrm{H}^{+}, \mathrm{M}$ & $0.4-0.6$ & $5-6$ & - \\
$\mathrm{Ci}$ & $0.7-2$ & $0.1-0.2$ & $\sim 10$
\end{tabular}


TABLE V. Summaty of $241_{\text {Am Recovery }}$

\begin{tabular}{|c|c|c|c|c|c|c|c|c|c|c|c|c|}
\hline Run Number & 7 AM-1 & $7 \mathrm{AM}-2$ & $7 A M-162$ & $7 \mathrm{AM}-3$ & $7 \mathrm{AM}-4$ & 7AM-6 & 7АM-6 & $8 A M-7$ & BAM-8 & 8АM-9 & $\underline{8 A M-10}$ & BAM-11 \\
\hline Precipitator & $10-5-1$ & $10-5-5$ & - & $10-5-1$ & $10-5-5$ & $10-5-1$ & $10-5-5$ & $10-5-1$ & $10-5-5$ & $10-5-1$ & $10-5-5$ & $10-5-1$ \\
\hline $\begin{array}{l}241_{\text {Am }} \text { batched to } \\
\text { PPTR, B }\end{array}$ & 69.4 & 65.3 & - & 67.7 & 66.4 & 71.0 & 71.8 & 71.0 & 71.0 & 72.5 & 12.5 & 152.7 \\
\hline $241_{\text {Am to waste, } 8}$ & 0.8 & 0.9 & - & 1.0 & 1.4 & 1.0 & 1.0 & 1.0 & 1.0 & 1.3 & 1.3 & 1.2 \\
\hline \multicolumn{13}{|l|}{ Product } \\
\hline Gross product, $B$ & 27.0 & 56.6 & 77.7 & 94.0 & 64.7 & 52.2 & 72.3 & 92.7 & 79.8 & 51.4 & 86.0 & 155.1 \\
\hline $241_{A m, g}$ & 22.6 & 49.4 & 66.4 & 81.2 & 56.1 & 45.6 & 63.2 & 80.2 & 69.0 & 44.7 & 74.8 & 134.2 \\
\hline $241_{A m, Z}$ & 83.5 & 87.3 & 85.5 & 86.4 & 86.7 & 87.3 & 87.0 & 86.5 & 86.4 & 86.8 & 87.0 & 86.5 \\
\hline $241_{\mathrm{AmO}_{2}, \mathrm{~g}}$ & 25.5 & 56.0 & 75.2 & 92.0 & 63.6 & 51.6 & 71.6 & 90.8 & 78.1 & 50.6 & 84.7 & 152.0 \\
\hline $241_{\mathrm{AmO}_{2}}, x$ & 94.5 & 98.9 & 96.9 & 97.8 & 98.2 & 98.9 & 98.5 & 98.0 & 97.8 & 98.3 & 98.5 & 98.0 \\
\hline \multicolumn{13}{|l|}{ Impurities } \\
\hline $\mathrm{Cr}, \mathrm{z}$ & 0.02 & 0.02 & 0.02 & 0.01 & 0.02 & 0.01 & 0.02 & 0.04 & 0.04 & 0.01 & 0.01 & $A S R^{a}$ \\
\hline Fe, $X$ & 0.05 & 0.05 & 0.06 & 0.04 & 0.06 & 0.07 & 0.03 & 0.05 & 0.06 & 0.05 & 0.05 & ASR ${ }^{a}$ \\
\hline $\mathbf{N i}, \mathbf{z}$ & 0.05 & 0.04 & 0.03 & 0.20 & 0.10 & 0.10 & 0.02 & 0.01 & 0.07 & 0.06 & 0.07 & $\operatorname{ASR}^{a}$ \\
\hline Pb, $\mathrm{z}$ & 0.40 & 0.40 & 0.25 & 0.50 & 0.40 & 0.50 & 0.40 & 0.35 & $(0.80)$ & 0.20 & 0.20 & $\mathrm{ASR}^{a}$ \\
\hline C,ppm & 222 & $<100$ & $<100$ & 213 & 344 & 313 & 302 & 110 & 260 & ASR ${ }^{n}$ & ASRa & ASR: \\
\hline Weight loss, $Z$ & 0.45 & 0.39 & 0.66 & 0.72 & 0.63 & 0.72 & 0.70 & 0.54 & 0.64 & 0.48 & 0.56 & ASR ${ }^{\mathrm{a}}$ \\
\hline \multicolumn{13}{|l|}{ Packaging } \\
\hline Package number & & & M001 & $M 006$ & M003 & $M 004$ & M002 & 100 & 101 & 102 & 103 & 104 \\
\hline $241_{\mathrm{Am}, \mathrm{g}}$ & & & 66.4 & 64.7 & 56.1 & 45.6 & 63.2 & 69.1 & 60.7 & 44.7 & 68.9 & 69.0 \\
\hline Package number & & & & M005b & & & & M005b & moosb & & M005b & 105 \\
\hline $241_{\mathrm{Am}}, \mathrm{g}$ & & & & 16.3 & & & & 11.3 & 9.8 & & 6.0 & 65.2 \\
\hline
\end{tabular}

a. Awaiting sample results.

b. M005 cumulative $241_{\mathrm{Am}}=43.3 \mathrm{~g}$. 


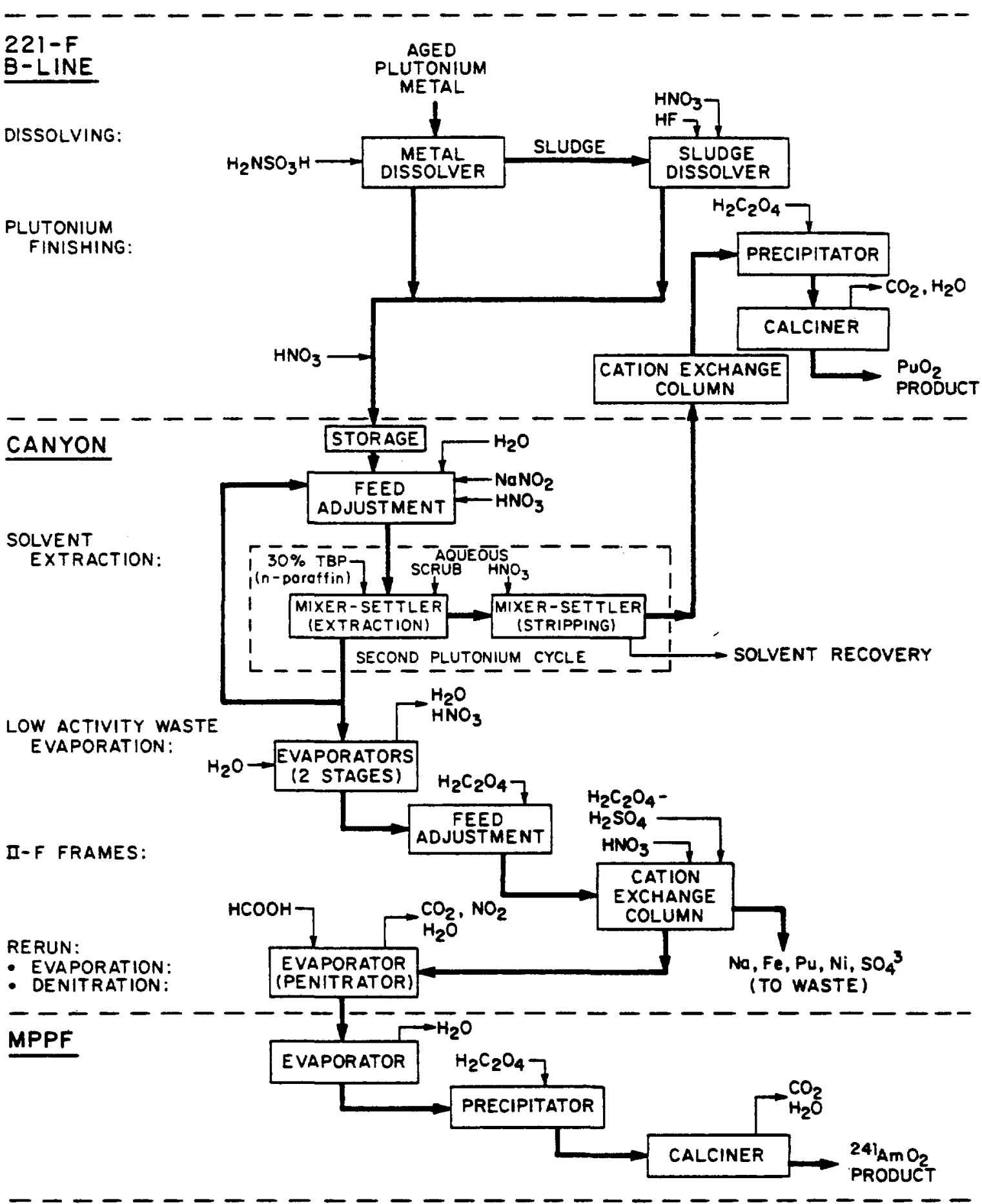

FIGURE 1. Process for Recovery of Americium-241 from Aged Plutonium Metal 


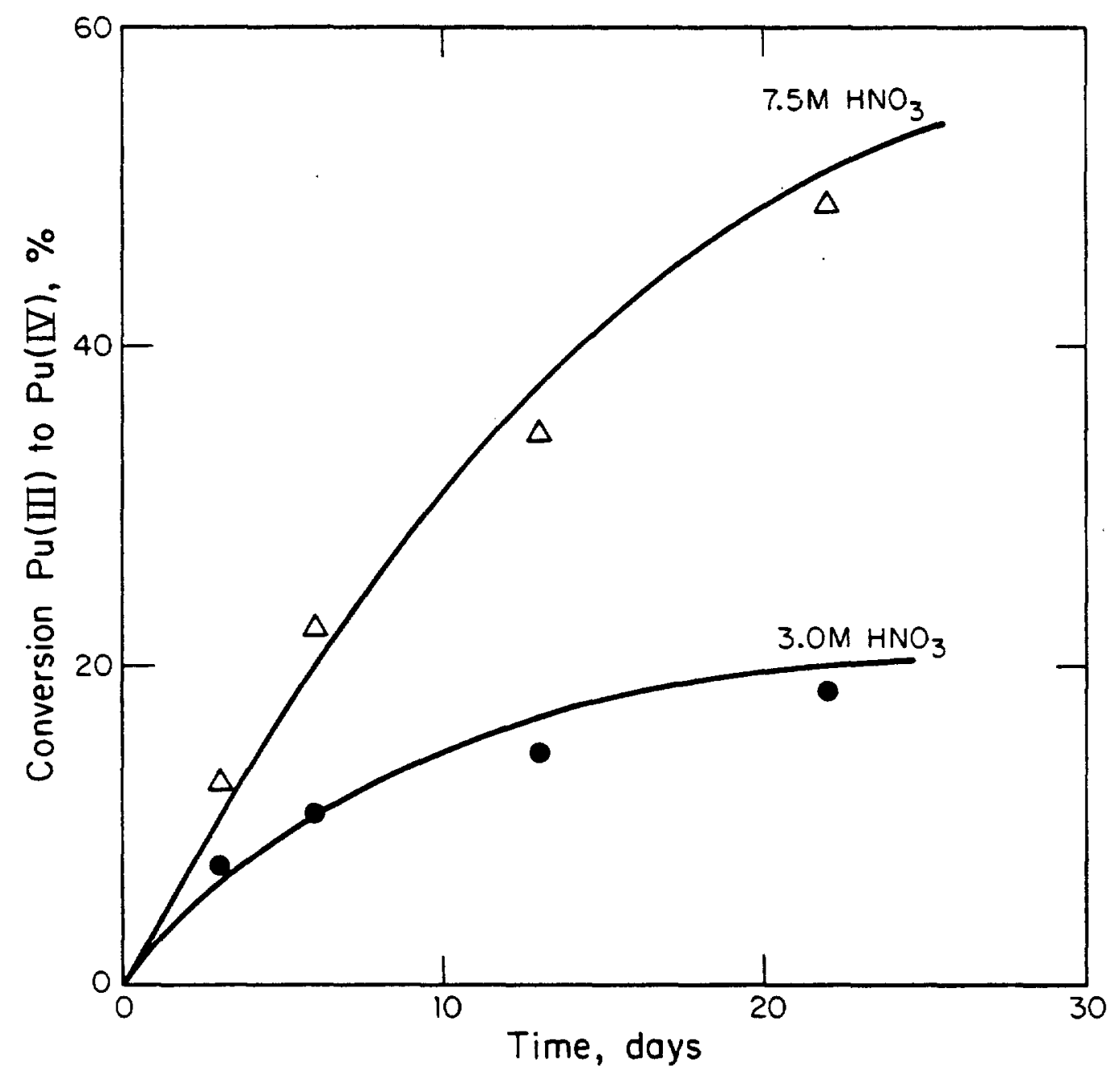

FIGURE 2. Radiolytic Oxidation of $P u(I I I)$ to $P u(I V)$ in Sulfamic Acid - Nitric Acid Solutions 


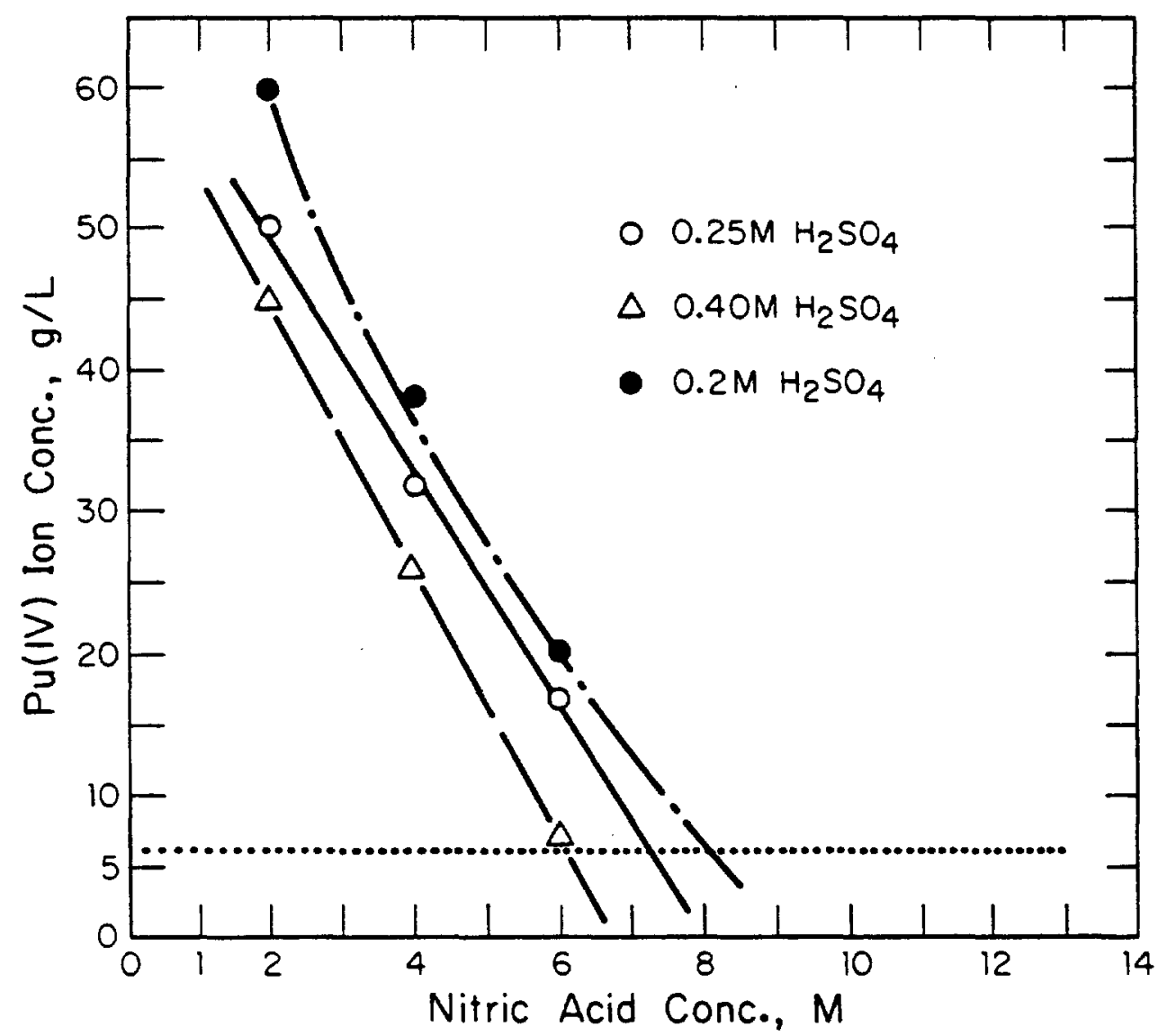

FIGURE 3. Calculated Equilibrium Concentrations of Pu(IV) in Nitric Acid Solutions Containing Sulfate Ions 


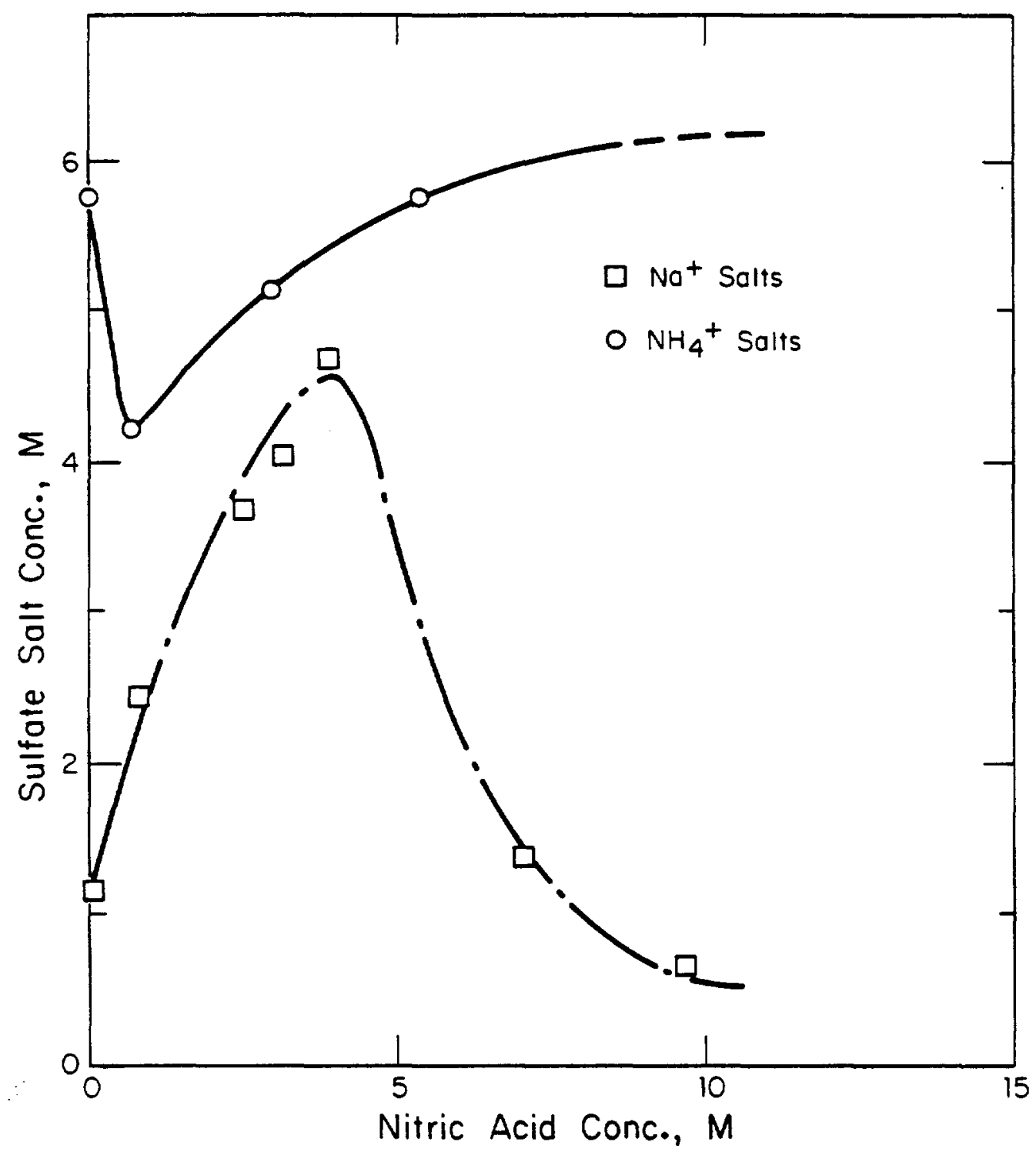

FIGURE 4. Solubility of Sulfate Salts in Nitric Acid Solutions 


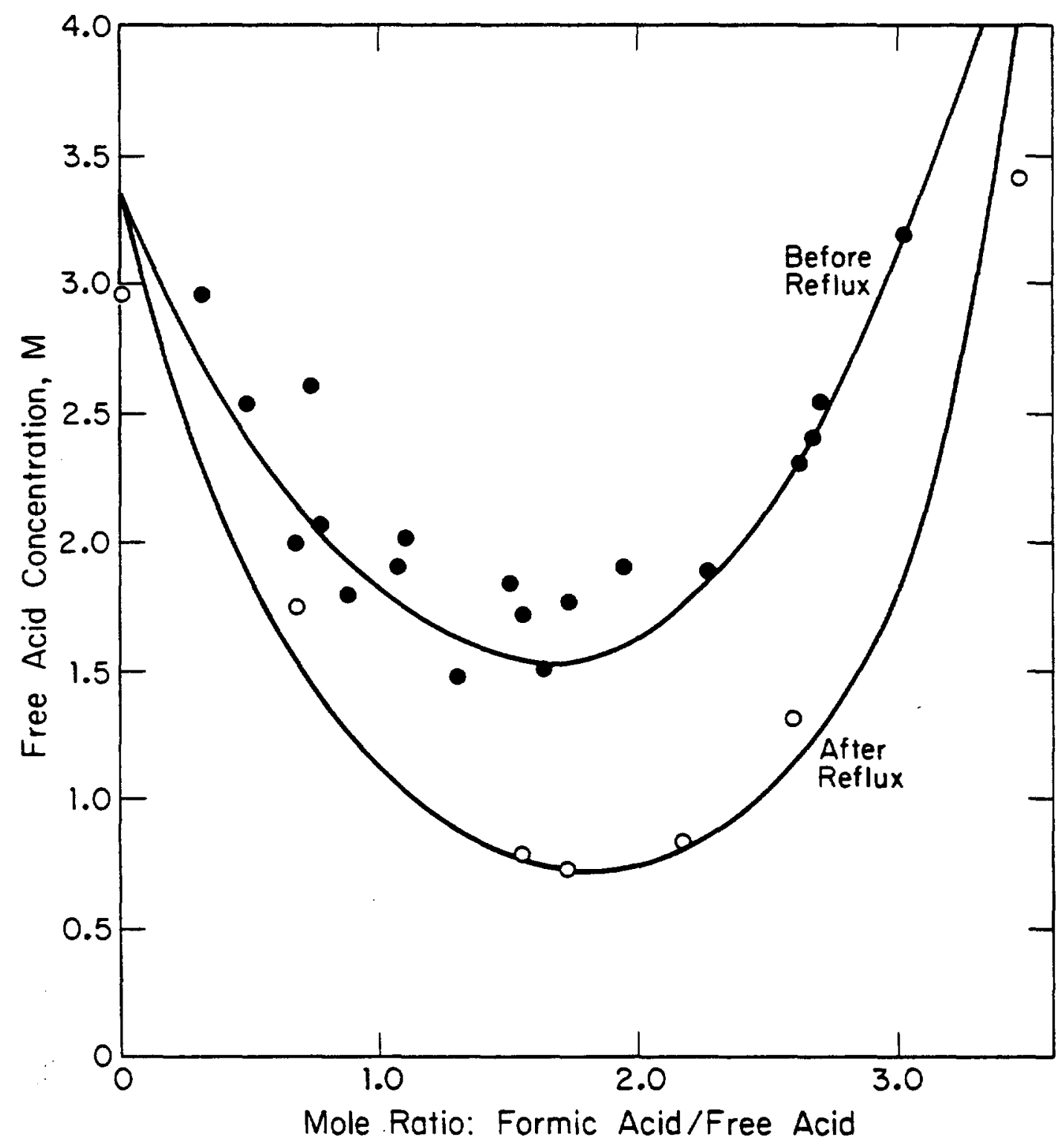

FIGURE 5. Formic Acid Denitration of $241_{\text {Am Solutions }}$ Containing Gross Quantities of Chromium Nitrate 